\title{
Radical pancreaticoduodenectomy in elderly patients: a feasible and adequate therapeutic option?
}

\author{
Marcello Garavoglia, Alberto Oldani*, Clemente De Rosa, Manuela Monni, Alfonso Terrone \\ From 26th National Congress of the Italian Society of Geriatric Surgery \\ Naples, Italy. 19-22 June 2013
}

\section{Introduction}

Pancreatic cancer remains one of the deadliest malignancies in the western emisphere despite improved surgical technique, chemotherapy and radiation therapy [1].

Due to the late diagnosis of pancreatic cancer, surgery is the gold standard method to increase the patients' overall survival; pancreaticoduodenectomy (or Whipple procedure), with lymph nodes dissection, is the standardized radical surgical procedure for pancreatic and periampullary tumors; it comprehends the removal of pancreas head, distal common bile duct, duodenum and the distal portion of the stomach (if the pylorus preserving technique is not used) and consequently the reconstruction with gastro-jejunal, bilio-jejunal anasthomosis, and Wirsunggastric or Wirsung-jejunal anasthomosis [2].

Pancreaticoduodenectomy is a complex high risk procedure that has infrequently performed until the 1980s, due to high mortality and morbidity rates; in the last 2decades, surgical techniques improved and postoperative adverse events became more infrequent; Cameron et al reported, on a series of 1000 consecutive pancreaticoduodenctomies, a mortality and morbidity rates of $1 \%$ and $4 \%$ respectively [3].

The aim of our study is to consider pancreatic surgery in a population of elderly patients, in order to evaluate mortality, morbidity and outcome.

\section{Methods}

From 01/01/1994 to 01/01/2013, 54 patients, 33 males $(61.11 \%)$ and 21 females (38.89\%) aged more than 70 years old (mean age 73 years, range 70-82), underwent radical pancreaticoduodenectoy for periampullar cancer.

\footnotetext{
* Correspondence: alberto.oldani@libero.it

Department of Surgery University of Eastern Piedmont "Amedeo Avogadro Hospital "Maggiore della Carità" Novara, Italy
}

Tumor localization was: pancreatic head in 32 cases (\%), Vater ampulla in 11 (20.37\%), distal common bile duct in 6 (11.11\%), duodenum in 4 (7.41\%).

In one case (1.85\%), pancreaticoduodenectomy was performed because of pancreatic head infiltration by right colon cancer.

\section{Results}

All patients underwent pancreaticoduodenectomy with Whipple-Child technique; macroscopic complete tumor ablation was always achieved.

Standard lymphadenectomy was performed in 43 cases (79.63\%), extended lymphadenectomy in 7 (12.96\%).

Mucosa-to-mucosa Wirsung-jejunal anastomosis was chosen in 34 cases $(62.96 \%) ; 19$ patients (35.19\%) were reconstructed with Wirsung-gastric anastomosis; in 1 case no pancreatic duct reconstruction was performed.

Perioperative mortality rate was $3.70 \%$; one patient died for postoperative acute pancreatitis and one for respiratory failure.

Morbidity was $14.81 \%$; 2 patients (3.70\%) developed postoperative peritoneal bleeding; we have also observed 3 cases of gastrointestinal bleeding (5.56\%), portal thrombosis in 2 patients $(3.70 \%)$ and one pancreatic fistula (1.85\%).

All postoperative complications have been managed conservatively except peritoneal bleedings, in which re operation has been necessary.

No differences in terms of morbidity have been demonstrated between the two methods of reconstruction (Wirsung-gastric versus Wirsung-jejunal anasthomosis); Wirsung-jejunal anasthomosis seems to prevent pancreatic atrophy in long surviving patients.

Overall 3 years and 5 years survival was respectively $22 \%$ and $15 \%$.

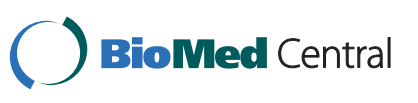


3 and 5 years survival rates were $24 \%$ and $16 \%$ in patients without lymph node involvement, $2 \%$ in patients with lymph node metastatization.

Causes of death have been liver metastasis (25.97\%), local recurrence (11.11\%), cardiovascular event (3.70\%).

\section{Conclusions}

The considerable increase of the aged population in western civilization within the next years will result in a rising incidence of pancreatic cancer. Until the year 2020 an increment of $20 \%$ of patients beyond 65 years old can be anticipated; until now only a few retrospective data analyses evaluating the perioperative and long term outcome in geriatric patients exist [4].

Our experience shows that radical surgery for periampullar malignancies is a good option in elderly patients; despite comorbidities we observed good results in terms of survival, mortality and morbidity, similar to what observed in younger patients.

\section{Published: 16 September 2013}

\section{References}

1. Kumar R, Herman JM, Wolfgang $\mathrm{CL}$, Zheng L: Multidisciplinary management of pancreatic cancer. Surg Oncol Clin N Am 2013, 22(2):265-87.

2. Furukawa $H$, Okada $S$, Saisho $H$, et al: Clinicpathologic features of small pancreatic adenocarcinoma. A collective study. Cancer 1996, 78:986-990.

3. Cameron JL, Riall TS, Coleman J, Belcher KA: One thousand consecutive pancreaticoduodenectomies. Ann Surg 2006, 244(1):10-5.

4. Nieß H, Kleespies A, Andrassy J, Pratschke P, Angele MK, Guba M, Jauch KW, Bruns CJ: Pancreatic cancer in the elderly: guidelines and individualized therapy. Chirurg 2013, 84(4):291-5.

doi:10.1186/1471-2482-13-S1-A23

Cite this article as: Garavoglia et al:: Radical pancreaticoduodenectomy in elderly patients: a feasible and adequate therapeutic option? BMC Surgery 2013 13(Suppl 1):A23.

\section{Submit your next manuscript to BioMed Central} and take full advantage of:

- Convenient online submission

- Thorough peer review

- No space constraints or color figure charges

- Immediate publication on acceptance

- Inclusion in PubMed, CAS, Scopus and Google Scholar

- Research which is freely available for redistribution

Submit your manuscript at www.biomedcentral.com/submit
C Biomed Central 